\title{
Resource management for flood response in Mexico
}

\author{
Oscar Rodriguez-Espindola ${ }^{1, *}$, Pavel Albores ${ }^{1}$, and Christopher Brewster ${ }^{2}$ \\ ${ }^{1}$ Aston Business School, Aston University, UK \\ ${ }^{2}$ Data Science Group, Toegepast-Natuurwetenschappelijk Onderzoek (TNO), the Netherlands
}

\begin{abstract}
Emergency logistics is acquiring a crucial role aiming to provide adequate care and support for people affected by catastrophic situations; dealing with a large number of stakeholders, scarcity of resources and high stakes. Considering the importance of balancing resources from different participants to improve operations, this research introduces a bi-criteria response optimisation model aiming to maximise the service provided to disaster victims while making efficient use of resources. The model provides support for relief distribution, inventory management and resource allocation. But beyond the optimisation of logistical decisions, the model is able to determine which organisations to use at the appropriate timeframe, so as to prevent shortages and convergence. The model is applied to a case study on a flood in Mexico in order to compare its results with real activities performed by authorities and draw conclusions.
\end{abstract}

\section{Introduction}

Natural disasters are a constant threat for many countries, affecting an average of over 200 million people per year between 2000 and 2014 [1]. Emergency logistics arises as the "process of planning, managing and controlling the efficient flows of relief, information, and services from the points of origin to the points of destination to meet the urgent needs of the affected people under emergency conditions" [2].

Under disaster circumstances government agencies play a major role in aiding vulnerable population. But these are just one of the actors, being supported also by NGOs, civil organisations and aid shipped from other countries [3].

Despite the common belief that sending every resource available is the best policy to provide support, recent experiences globally have shown that it is important to manage closely resources available, to deploy the right organisations at the right time.

The purpose of this research is to provide a model capable of providing support for relief distribution and resource allocation considering the participation of different organisations. 


\section{Literature review}

Relief distribution refers to the dispatch of different commodities to affected areas swiftly and efficiently [4]. This is a very challenging activity faced by responders [5] and also a crucial factor for high performance operations[6].

Using multi-objective approaches, Huang, Jiang [7] accounted for human suffering with three objectives; maximise lifesaving utility (i.e. preference of relief resources), minimise delay cost (similar to deprivation cost), and minimise the sum of squares of the distances between the demand fill rates and the ideal demand rate. Adivar and Mert [8] looked at the coordination of international relief items using fuzzy logic to provide a collectiondistribution plan. The model minimises cost and maximises the minimum credibility of international organisations to deliver relief items on time. Incorporating uncertainty of relief demand by using forecasting, clustering and dynamic relief supply for logistic operations related to distribution, Sheu [5] designed a model to maximise fill rate and minimise distribution cost.

Chang, Tseng [9] designed two optimisation models with different organisation levels for floods. The models cluster demand and determine local rescue bases to minimise total cost. More recently, Altay [10] developed a static model to allocate response personnel, facilities, supplies and equipment to disaster-affected jurisdictions. The alternative objective functions are to minimise total deployment time or minimise maximum response time. Including uncertainty in the state of road network, Edrissi, Poorzahedy [11] presented a formulation to coordinate agencies considering strengthening structures around vulnerable areas, retrofitting transportation links and locating and equipping emergency response centres. They introduced a dynamic version of the preparedness optimisation model to ship relief aid in the response stage.

There is only a handful of papers considering the importance of sharing resources, whether between teams [e.g. 10, 12], regions [e.g. 13], organisations [e.g. 8] or other agents [e.g. 11]. In the literature, however, there is no dynamic formulation for relief distribution optimising the number of actors involved determining the deployment and withdrawal of different agencies. Having the right expertise on the field at the right time are factors that can affect operational success in disaster response.

The purpose of this research is to provide a model incorporating several actors to identify the optimal combination of organisations and resources required per period.

\section{Model design}

The model developed in this research can provide support for decision-making for that interval of time. The dynamic formulation includes two objective functions, one related to cost and another focused on fill rate, thereby balancing efficiency and effectiveness. The model can determine what actors to involve and the appropriate moment for them to participate on the field.

\subsection{Notation and definitions}

The notation considered for the design of the model is presented as follows:

Sets

I Supply facilities, $I=\{1,2,3, \ldots, I)$

J Demand areas, $J=\{1,2,3, \ldots, J)$

M Transportation modes, $M=\{1,2,3, \ldots, M)$

N Products, $N=\{1,2,3, \ldots, N)$ 
O Organisations, $O=\{1,2,3, \ldots, O)$

T Periods of time, $T=\{1,2,3, \ldots, T)$

Parameters

RPC Space covered per distribution centre employee

RPS Number of people covered per shelter employee

RPH Number of people covered per healthcare team

APDC Percentage of staff needed for partial opening of DCs, $0 \leq A P D C \leq 1$

OND Number of days for relief distribution per period

$\mathrm{CP}_{\mathrm{n}} \quad$ Procurement cost per product $n$

$\mathrm{CI}_{\mathrm{j}} \quad$ Storage capacity of shelter $j$

$\mathrm{A}_{\mathrm{i}} \quad$ Capacity of DC $i$

Type $_{\mathrm{j}} \quad$ Type of demand area, type $e_{j} \in[0,1]$

VOL $_{\mathrm{n}} \quad$ Volume per product $n$

WEI $_{\mathrm{n}} \quad$ Weight per product $n$

$\mathrm{PAC}_{\mathrm{ot}} \quad$ Available personnel from organisation $o$ for DC operation at period $t$

$\mathrm{PAS}_{\mathrm{ot}} \quad$ Available personnel from organisation $o$ for shelter operation at period $t$

$\mathrm{PAH}_{\mathrm{ot}} \quad$ Available s from organisation $o$ for healthcare at period $t$

$\mathrm{PAD}_{\mathrm{ot}} \quad$ Available personnel from organisation $o$ for distribution at period $t$

$\mathrm{TRP}_{\mathrm{ot}} \quad$ Total operative staff available per organisation $o$ at period $t$

$\mathrm{G}_{\mathrm{n}} \quad$ Conversion factor for each product $n$

$\mathrm{PRI}_{\mathrm{n}} \quad$ Priority of product $n$

$\mathrm{SL}_{\mathrm{n}} \quad$ Minimum product fill rate percentage every three periods, $0 \leq \mathrm{SL}_{n} \leq 1$

$\mathrm{D}_{\mathrm{it}} \quad$ Number of people aided in demand area $j$ at time $t$

$\mathrm{EP}_{\mathrm{k}} \quad$ Population to be sheltered per demand area $k$

$\mathrm{F}_{\mathrm{m}} \quad$ Weight vehicle capacity of mode $m$

$\mathrm{AVD}_{\mathrm{m}} \quad$ Available number of trips per day per mode $m$

$\mathrm{RDP}_{\mathrm{m}} \quad$ Distribution personnel required per mode $m$

WAGE $_{\mathrm{ot}} \quad$ Wages paid for the activation of organisation $o$ at period $t$

$\mathrm{CS}_{\mathrm{ijm}} \quad$ Delivery cost from DC $i$ to shelter $j$ by mode $m$

$\mathrm{IPD}_{\text {int }} \quad$ Product demand at demand point $j$ of product type $n$ at period $t$

$\mathrm{CON}_{\mathrm{ijmt}} \quad$ Connectivity between DC $i$ and shelter $j$ by mode $m$ at period $t$

$\mathrm{TV}_{\text {mot }}$

Number of vehicles available of type $m$ per organisation $o$ at period $t$

$\mathrm{SA}_{\mathrm{ijm}}$

$\mathrm{SC}_{\text {not }}$

$\mathrm{DI} 0_{\text {inot }}$

$\mathrm{SI0} 0_{\text {inot }}$

$\mathrm{PC}_{\text {iot }}$

$\mathrm{PSO}_{\text {iot }}$

$\mathrm{PHO}_{\text {jot }}$

$\mathrm{PD} 0_{\text {imot }}$

Variables

DSAT $_{\text {int }}$ Availability for distribution from $i$ to $j$ by mode $m, S A_{i j m} \in[0,1]$

Supply capacity of product $n$ from organisation $o$ at period $t$

TRAV $_{\text {ijmt }}$ Initial inventory of product $n$ from organisation $o$ at DC $i$ at period $t$,

$\mathrm{NVH}_{\mathrm{it}}$

$\mathrm{PVH}_{\mathrm{it}}$ Initial inventory of product $n$ from organisation $o$ at $j$ at period $t$

$\mathrm{NVS}_{\mathrm{it}}$ Initial staff from organisation $o$ at DC $i$ at period $t$

$\mathrm{PVS}_{\mathrm{jt}}$

$\mathrm{APC}_{\mathrm{iot}}$

Initial staff for shelter care from organisation $o$ at shelter $j$ at period $t$

Initial staff for healthcare from organisation $o$ at shelter $j$ at period $t$

Initial personnel for distribution from organisation $o$ at DC $i$ at period $t$

$\mathrm{DPC}_{\text {iot }}$

$\mathrm{APS}_{\text {iot }}$

Demand of product $n$ not fulfilled on shelter $j$ at period $t$

Number of trips deployed from DC $i$ to shelter $j$ by mode $m$ at period $t$

Expected number of people without healthcare at shelter $j$ at period $t$

Surplus of people covered for healthcare at shelter $j$ at period $t$

Number of people without shelter attention at shelter $j$ at period $t$

Surplus of people covered for shelter attention at shelter $j$ at period $t$

Increase of DC personnel from organisation $o$ in facility $i$ at period $t$

Decrease of DC personnel from organisation $o$ in facility $i$ at period $t$

Increase of shelter personnel from organisation $o$ in facility $j$ at period $t$ 


$\begin{array}{ll}\mathrm{DPS}_{\text {iot }} & \text { Decrease of shelter staff from organisation } o \text { in facility } j \text { at period } t \\ \mathrm{APH}_{\text {iot }} & \text { Increase of healthcare staff from organisation } o \text { in facility } j \text { at period } t \\ \mathrm{DPH}_{\text {iot }} & \text { Decrease of healthcare staff from organisation } o \text { in facility } j \text { at period } t \\ \mathrm{APD}_{\text {imot }} & \text { Increase of distribution staff from organisation } o \text { in } i \text { at period } t \\ \mathrm{DPD}_{\text {imot }} & \text { Decrease of distribution staff from organisation } o \text { in } i \text { at period } t \\ \mathrm{MAD}_{\text {it }} & \text { Number of people with relief shortages at demand point } j \text { at period } t \\ \mathrm{TSC}_{\text {int }} & \text { Amount of product } n \text { consumed at demand point } j \text { at period } t \\ \mathrm{INV}_{\text {int }} & \text { Number of items of type } n \text { stored at demand point } j \text { at period } t \\ \mathrm{IL}_{\text {int }} & \text { Number of items of type } n \text { stored at DC } i \text { at period } t \\ \mathrm{UFR} & \text { Total unfulfilled demand } \\ \mathrm{Cost} & \text { Total cost } \\ \mathrm{W}_{\text {ot }} & \text { Whether to activate organisation } o \text { or not at period } t \\ \mathrm{SHIP}_{\text {iimnt }} & \text { Relief of type } n \text { delivered from DC } i \text { to shelter } j \text { by mode } m \text { at period } t \\ \mathrm{PC}_{\text {iot }} & \text { Personnel from organisation } o \text { allocated to DC } i \text { at period } t \\ \mathrm{PS}_{\text {iot }} & \text { Personnel from organisation } o \text { allocated to shelter } j \text { at period } t \\ \mathrm{PH}_{\text {iot }} & \text { Staff from organisation } o \text { allocated for healthcare to shelter } j \text { at period } t \\ \mathrm{PD}_{\text {imot }} & \text { Staff from organisation } o \text { to be allocated for distribution to } i \text { at period } t \\ \mathrm{AV}_{\text {imot }} & \text { Vehicles of type } m \text { from organisation } o \text { allocated at DC } i \text { at period } t \\ \mathrm{SUP}_{\text {inot }} & \text { Amount of product } n \text { from organisation } o \text { supplied to DC } i \text { at period } t\end{array}$

\subsection{Model formulation}

The response optimisation model is looking to balance resources available during the whole disaster. The model chooses which agencies to activate depending on the circumstances and the stage of the emergency, designing a policy tailored to the situation. The formulation of the model is presented as follows:

MinCost $=\sum_{o} \sum_{t} W_{\text {ot }} * \mathbf{W A G E}_{\text {ot }}+\sum_{i} \sum_{n} \sum_{0} \sum_{\mathrm{t}} \mathbf{C P}_{\mathbf{n}} * S U P_{\text {inot }}+$ $\sum_{i} \sum_{j} \sum_{m} \sum_{t} \mathbf{C S}_{1 j \mathrm{~m}} * T R A V_{i j m t}$

$\operatorname{MinUFR}=\sum_{j} \sum_{t}\left(M A D_{j t}+N V H_{j t}+N V S_{j t}\right)$

s.t.

$$
\begin{array}{ll}
M A D_{j t}=\frac{\sum_{n} D S A T_{j n t} * \mathrm{PRI}_{\mathrm{n}} * G_{\mathrm{n}}}{\sum_{n} \mathrm{PRI}_{\mathrm{n}}} & \forall j, \mathrm{t} \\
D S A T_{j n t}=I P D_{j n t}-T S C_{j n t} & \forall j, n, t \\
T S C_{j n t}+T S C_{j n t+1}+T S C_{j n t+2} \geq\left(I P D_{j n t}+I P D_{j n t+1}+I P D_{j n}\right. & \forall j, n, t \\
I L_{i n t}=I L_{i n(t-1)}+\sum_{0} S U P_{\text {inot }}-\sum_{j} \sum_{m} S H I P_{i j m n t}+\sum_{0} D I 0_{i 1} & \forall i, n, t \\
I N V_{j n t}=I N V_{j n(t-1)}+\sum_{i} \sum_{m} S H I P_{i j m n t}-T S C_{j n t}+\sum_{0} S I 0_{j n c} \forall j, n, t
\end{array}
$$




$$
\begin{aligned}
& \sum_{i} S U P_{\text {inot }} \leq S C_{\text {not }} * W_{\text {ot }} \\
& A_{i} \geq \sum_{n} I L_{\text {int }} * \text { VOL }_{\mathbf{n}} \\
& C I_{j} * \mathrm{TYPE}_{1} \geq \sum_{n} I N V_{j n t} * \mathrm{VOL}_{\mathrm{n}} \\
& \text { APDC } * A_{i} \leq \mathbf{R P C} * \sum_{0} P C_{\text {iot }} \\
& D_{j t} * \mathbf{T Y P E}_{1} \leq \mathbf{R P S} * \sum_{o} P S_{j o t}+N V S_{j t}-P V S_{j t} \\
& D_{j t} * \mathbf{T Y P E}_{j} \leq \mathbf{R P H} * \sum_{o} P H_{j o t}+N V H_{j t}-P V H_{j t} \\
& P C_{\text {iot }}=P C_{\text {io(t-1) }}+A P C_{\text {iot }}-D P C_{\text {iot }}+P C 0_{\text {iot }} \\
& P S_{j o t}=P S_{j o(t-1)}+A P S_{j o t}-D P S_{j o t}+P S 0_{j o t} \\
& P H_{j o t}=P H_{j o(t-1)}+A P H_{j o t}-D P H_{j o t}+P H 0_{j o t} \\
& P D_{\text {imot }}=P D_{\text {imo }(t-1)}+A P D_{\text {imot }}-D P D_{\text {imot }}+P D 0_{\text {imot }} \\
& \sum_{i} P C_{\text {iot }}=\mathbf{P A C}_{\text {ot }} * W_{\text {ot }} \\
& \sum_{j} P S_{j o t}=\mathbf{P A S}_{\mathrm{ot}} * W_{\text {ot }} \\
& \sum_{j} P H_{\text {iot }}=\mathbf{P A H}_{\mathrm{ot}} * W_{\text {ot }} \\
& \sum_{i} \sum_{m} P D_{\text {imot }} \leq \mathbf{P A D}_{\text {ot }} * W_{\text {ot }} \\
& \mathbf{T R P}_{\text {ot }} * W_{\text {ot }} \geq \sum_{i} P C_{\text {iot }}+\sum_{j} P S_{j o t}+\sum_{j} P H_{j o t}+\sum_{i} \sum_{m} P D_{i m} \forall o, t
\end{aligned}
$$

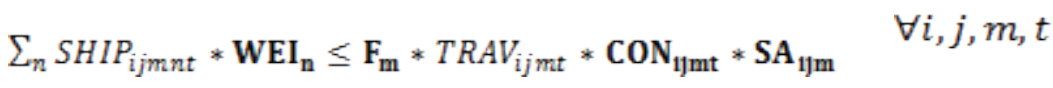

$$
\begin{aligned}
& \sum_{j} T R A V_{i j m t} \leq \mathbf{O N D} * \sum_{o} A V_{i m o t} * \mathbf{A V D}_{\mathbf{m}} \\
& A V_{\text {imot }} \leq \frac{P D_{\text {imot }}}{\operatorname{RDP}_{\mathrm{m}}} \\
& \sum_{i} A V_{\text {imot }} \leq \mathbf{T V}_{\text {mot }} * W_{\text {ot }} \\
& \forall i, m, t \\
& \forall i, m, o, t \\
& \forall m, o, t
\end{aligned}
$$


Expression (1) minimises cost in terms of the number of organisations involved, procurement cost and transportation cost. Function (2) seeks the minimisation of the total unfulfillment of shelter care, healthcare and relief distribution across all demand areas and all periods. Constraint (3) determines the unfulfillment level depending on the priority of the product from the number of unsatisfied demand established on equation (4). Expression (5) is enforcing that the combination of the consumption at every demand area of every product every three periods is at least a certain percentage of the total demand at all shelters over the same periods. Equations (6) and (7) determine the levels of inventory of DCs and demand areas, respectively. Expression (8) makes sure that items procured and delivered are aligned with the supply capacity from the organisations activated. Constraints (9) and (10) restrict the storage capacity of DCs and demand areas, respectively. Expression (11) ensures a minimum number of personnel allocated to DCs even for partial opening, whereas equations (12) and (13) determine the shortage or surplus of personnel for shelter attention and healthcare. Constraints (14), (15), (16) and (17) determine the number of staff allocated for DC management, shelter care, healthcare and distribution including the rotation of personnel, whereas expressions (18), (19), (20) and (21) ensure the maximum number of staff from the activated organisations is not surpassed. Equation (22) forces the number of operative resources used per agency to be lower than the number of personnel available, including the term for healthcare teams if and only if one member is available for operative support. Expression (23) determines the number of trips from each DC to each shelter for distribution, constraint (24) establishes the number of vehicles required, equation (25) the number of employees needed, and expression (26) bounds the maximum number of vehicles available. Finally, the declaration of binary and integer variables is presented.

\section{Case study: 2010 Flood at Veracruz, Mexico}

\subsection{Data gathering}

A total of 62 Freedom of Information (FOI) were filed to regional agencies and 121 requests were made to National governmental bodies involved in the flood. The agencies involved in field operations included: DICONSA, National System of Family Development (DIF), Social Security Mexican Institute (IMSS), Civil Protection (PC), National Health Ministry (SMEXICO), State Health Ministry (SVERACRUZ), the military (SEDENA), Ministry of Interior (SEGOB) and the Navy (SEMAR).

The information gathered was in terms of relief items, prepositioned stock, shelters used, number of people sheltered per period, distribution centres activated costs, required number of employees per activity and personnel available per agency.

\subsection{Solution of the model}

Using the information the model was solved using the weighted-sum method and the $\varepsilon$ constraint method with loops of 150 iterations and a time limit of 600 seconds per iteration. A total of 142 non-dominated solutions were obtained.

More data was collected from the participating organisations. The purpose was to recreate the situation obtained according to the real activities. The only information unavailable was related to allocation of resources and services, which was optimised to obtain the best possible outcome that could have been achieved by authorities. The comparison can be seen in Figure 1. 


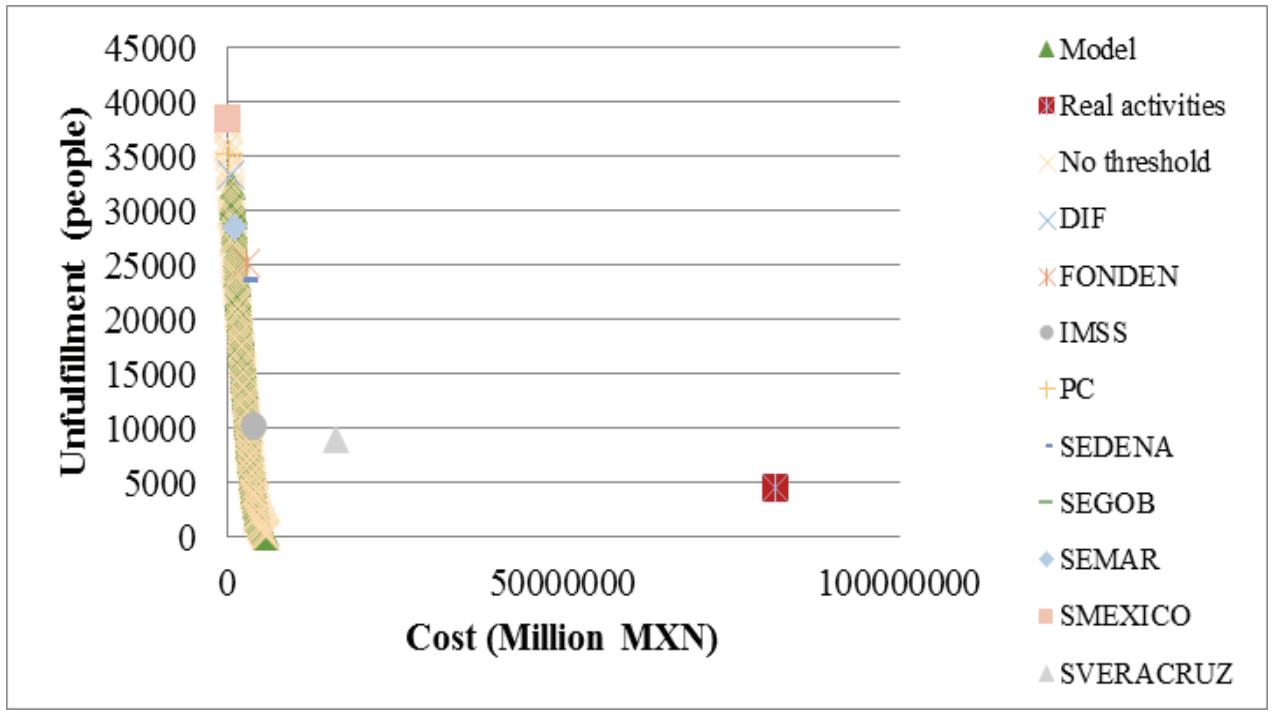

Fig. 1. Comparison of the model to independent decision-making and real activities

The figure shows how independent decision-making was not a suitable policy for the disaster as there is no organisation capable of coping with the conditions of the disaster. It can also be seen that assuming a coordinated approach the real decisions made by authorities represented an acceptable fill rate but at a very high cost compared to the potential solution delivered by the model.

\section{Conclusions}

This research introduced a novel dynamic optimisation model for disaster management considering the involvement of several organisations. Resource management is a significant component of response activities such as relief distribution and inventory management. The results of the model showed the potential to handle several organisations and deploy them according to the circumstances. The model was capable of providing a $100 \%$ of satisfaction rate with the resources available without the need to involve all of the organisations that participated in reality in the disaster.

The comparison with independent decision-making showed the incapability of any of the organisations involved to handle the situation on their own, whereas the comparison to real activities exhibited the room of improvement for future operations in terms of cost and fill rate.

The result of the study highlights the importance of considering the management of resources for logistical decisions in disaster management and the need to integrate the different actors to avoid duplications of effort and achieve more successful operations.

\section{References}

1. CRED, Advanced Search. 2015, Université Catholique de Louvain: Brussels, Belgium.

2. J.B. Sheu, Transp. Res. Part E: Log. and Transp. Rev. 43, 6, 655-659 (2007)

3. I.M. Nolte, E.C. Martin, S. Boenigk, Pub. Man. Rev. 14, 6, 707-730 (2012)

4. L. Özdamar, E. Ekinci, B. Küçükyazici, Annals of Oper. Res. 129, 1, 217-245 (2004)

5. J.B. Sheu, Transp. Res. Part E: Log. and Transp. Rev. 2007. 43, 6, 687-709 (2007) 
6. L.E. De la Torre, I.S. Dolinskaya, K.R. Smilowitz, Soc. Econ. Plan. Sci. 46, 1, 88-97 (2012)

7. K. Huang, Y. Jiang, Y. Yuan, L. Zhao, Transp. Res. Part E: Log. and Transp. Rev, 75, 1-17 (2015)

8. B. Adıvar, A. Mert, Fuzzy Opt. \& Dec. Making, 9, 4, 413-433 (2010)

9. M.S. Chang, Y.L. Tseng, J.W. Chen, Transp. Res. Part E: Log. and Transp. Rev. 43, 6, 737-754 (2007)

10. N. Altay, IMA J. of Man. Math. 24, 2, 253-266 (2013)

11. Edrissi, H. Poorzahedy, H. Nassiri, M. Nourinejad, Eur. J. of Op. Res. 229, 1, 261-275, (2013)

12. G.G. Brown, A.L. Vassiliou, Nav. Res. Log. 40, 1, 1-23 (1993)

13. H. Arora, T.S. Raghu, A. Vinze, Dec. Sup. Syst. 50, 1, 304-315 (2010) 